\title{
Evaluation of Liquefaction Potential of New Caledonian Nickel Ores
}

\author{
Samar Daoud ${ }^{1(\bowtie)}$, Imen Said ${ }^{1}$, Samir Ennour $^{2}$, \\ and Mounir Bouassida ${ }^{1}$ \\ ${ }^{1}$ ENIT, Université de Tunis El Manar - Ecole Nationale d'Ingénieurs de Tunis, \\ LR14ES03-Ingénierie Géotechnique, Tunis, Tunisia \\ samar.daoud1989@gmail.com, imensaid2@gmail.com, \\ mounir.bouassida@fulbrightmail.org \\ 2 Mining Engineering, MECATER, Rue Ibn Zohr, Immeuble Alizé, \\ 2015 Le Kram, Tunisia \\ samir.ennour@mecater.com
}

\begin{abstract}
Although Nickel ores are generally characterized as plastic to very plastic silts they do liquefy under specific conditions. In fact, it was reported that New Caledonian Nickel ores (NCNo) can undergo liquefaction during their maritime transportation under wave motions. The purpose of this research is to develop a new empirical method to evaluate the liquefaction potential of these soils. First, the study consists on interpreting physical and mechanical characterization tests carried on Nickel ore samples originating from different sites of New Caledonia. This analysis permitted to conclude on the heterogeneity of NCNo and enabled the identification of three major types namely, laterites, earthy and grainy saprolites. The classification of these groups was based on the grain size distribution and the Atterberg limits tests. Afterwards, a review of the existing liquefaction potential evaluation methods is elaborated. The application of these methods to the case of NCNo has not allowed concluding on the liquefaction susceptibility of this material. Finally, a new method specific to each NCNo type was introduced based on the physical and mechanical test results.
\end{abstract}

\section{Introduction}

New Caledonian Nickel ores (NCNo) are obtained from open-cast mines and shipped to smelters located in China, Japan, Australia, Korea, etc. Several case histories of ore carriers capsize have been reported due to liquefaction of the transported material. According to The International Maritime Solid Bulk Cargoes Code (IMSBC 2008), these kind of cargoes are classified as Group A materials where several laboratory tests namely the Flow Table, the Penetration test and the Proctor/Fagerberg test are recommended to predict the risk of liquefaction before transport.

With reference to Koromila et al. (2013), cargoes that are at risk of liquefaction are those containing at least some fine particles and moisture and further mined or stored in exposed areas which allow the soaking up of large amounts of water. Such cargoes at the time of loading are typically in granular state and look like dry. However, whilst at 
sea, they are subject to agitation due to the engine vibration; ship's rolling as well as swell impact. The oscillatory ship movement leads to resettling of the cargo particles and compaction of the inter-granular spaces. This compaction raises the water pressure sharply, forcing the particles apart, potentially leading them to lose direct contact. The cargo loses its shear strength and thus conditions are created for the material to behave like a liquid, i.e. to liquefy (IMSBC 2008). As a result, this latter can lead to a "free surface effect" that may upset the carrier's balance and causes it to capsize in heavy swells.

The existing guidelines for identifying potentially liquefiable soils are generally divided into two major types. The first one covers the laboratory tests enabling to obtain accurate results especially when carried out on undisturbed samples. In fact, many experimental tests carried out in laboratories are enough efficient since they are able to reproduce similar solicitations and field conditions to evaluate the susceptibility of a type of soil to liquefaction. The most famous tests are the direct shear test, the cyclic triaxial shear test, shaking table test... The second method is the empirical approaches developed based on various combinations of characterization test results, namely the Atterberg limits, the grain size characteristics, and the natural water content. These methods developed by researchers like Tsuchida (1970), Seed and Idriss (1982), Andrews and Martin (2000), are deduced from field observations of liquefied and non-liquefied soils after famous earthquakes. By means of these approaches, it is possible to determine the likelihood of liquefaction triggering in a particular soil under a given earthquake. Thus, the choice of this alternative is justified by its simplicity and cost-effectiveness.

Unfortunately, the efficiency and accuracy of these methods are still questioned since they do not provide reliable results covering all types of soil and solicitations. Indeed, although researchers had made efforts on identifying the susceptible liquefiable soil types based on mechanical and physical characterization tests, there is still no qualitative and quantitative parameter in the Geotechnical field that could be used as an evaluation tool of liquefaction susceptibility.

The final aim of this study is the elaboration of a method to evaluate the liquefaction potential of NCNo prior to their shipping in order to avoid further incidents. First, the study consists of interpreting physical and mechanical characterization tests carried on Nickel ore samples originating from different sites of New Caledonia. This analysis enabled the classification of the tested specimens into different groups and the identification of three major types of NCNo. Afterwards, an evaluation of the liquefaction potential of NCNo by means of the existing approaches is elaborated. Finally, a new method to assess the liquefaction susceptibility adapted for each type of NCNo is introduced.

\section{Data Base Discussion and Interpretation}

The first step in assessing the risk of liquefaction is to identify potentially liquefiable soils according to their physical characteristics (grain size distribution, water content, Atterberg limits...) and mechanical properties. 
As part of Rheolat project, a series of physical and mechanical tests were conducted on numerous Nickel ore samples originating from different sites and mines of New Caledonia. Grain size distribution, Atterberg Limits and Cyclic triaxial shear tests were carried out by CERMES laboratories. Flow Table Tests were elaborated by SLN*.

In this section, the different test results are presented, discussed and interpreted in order to classify the tested NCNo samples into groups and in final aim to evaluate their liquefaction potential.

\subsection{Physical Characterization of NCNo}

\section{Grain Size Distribution Test Results}

Particle size analysis were conducted on 24 samples of NCNo to allow determination of the soil nature corresponding to standard XP CEN TS/ISO 17892-4.

The obtained curves by combining dry sieving and sedimentometry results, point out the heterogeneity of NCNo. The representation of grain size distributions on the same graph in Fig. 1 enables distinguishing three major grading ranges. It is concluded that each of these latters corresponds to a type of NCNo.

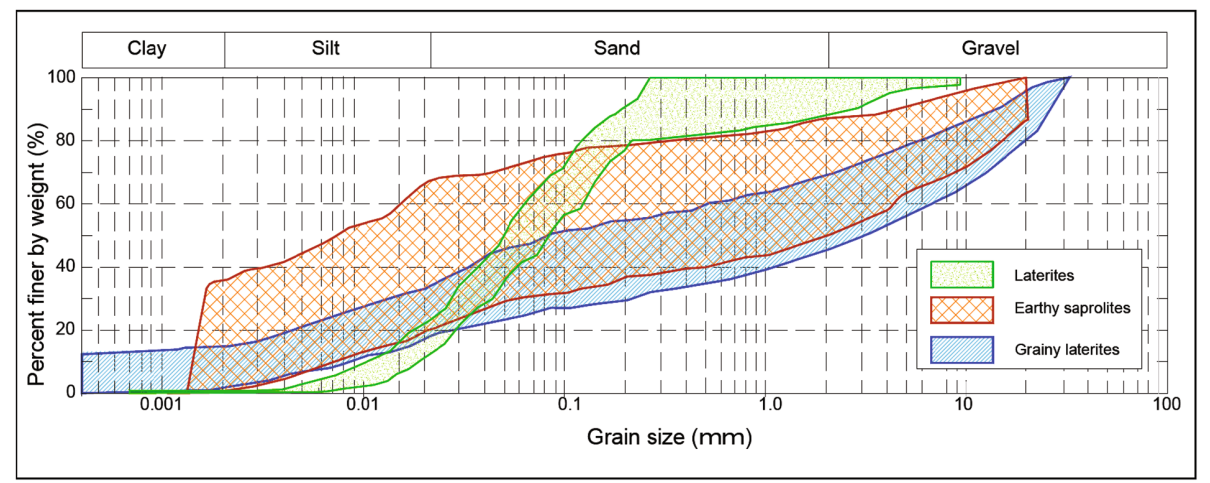

Fig. 1. Grading ranges of the three identified NCNo groups

Group 1: Laterites which are silty sands having most particles smaller than $80 \mu \mathrm{m}$. Group 2: Earthy saprolites that are sandy silts containing a small fraction of coarse particles (>2 mm) not exceeding $30 \%$.

Group 3: Grainy saprolites which are grainy sands having a high fraction of coarse particles $(>30 \%)$.

\section{Atterberg Limits Test Results}

The Atterberg limits test is also carried out by CERMES laboratories on the same samples cited above corresponding to standard NF P 94-051. It is used in order to characterize the plasticity of a soil since it can influence the soil liquefaction properties. 
The interpretation of the Atterberg limit test by representing the results on the Casagrande graph confirms the repartition of the tested samples into three distingable groups as shown in Fig. 2. It is also concluded that all NCNo are highly plastic silts.

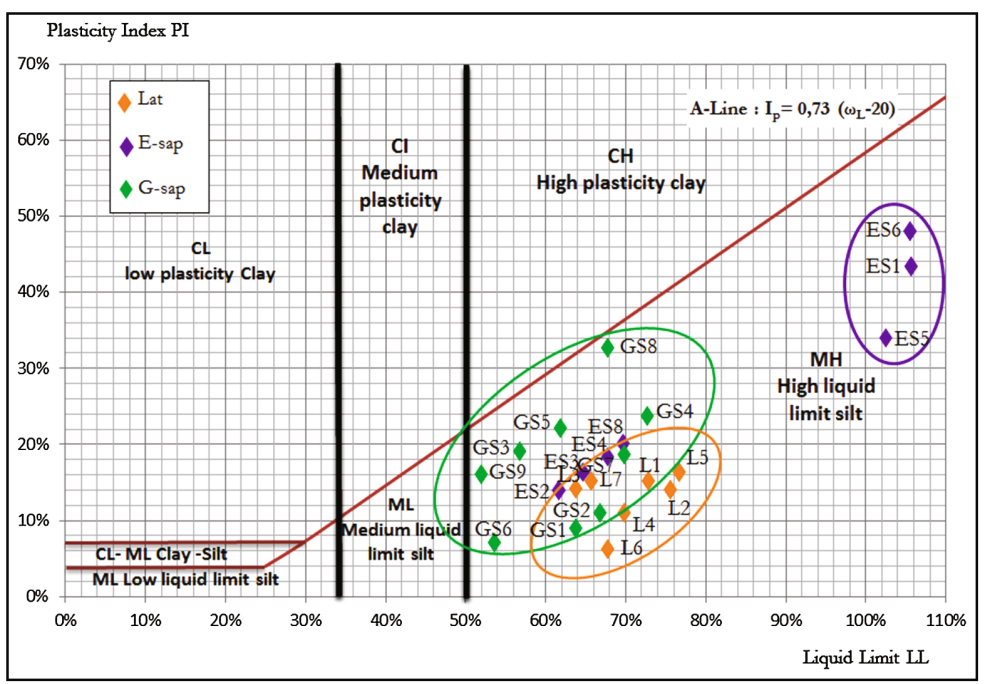

Fig. 2. Representation of Nickel ore tested samples on the Casagrande Diagram

\subsection{Mechanical Characterization of NCNo}

First, a series of consolidated undrained tests with measure of pore water pressure $(\mathrm{CU}+\mathrm{u})$ were carried out by CERMES laboratories on samples representative of the three different NCNo groups. Second, Flow Table tests have been elaborated by SLN laboratories on NCNo. The results of these mechanical testes are presented and interpreted in this paragraph. The critical water content is defined as the value above which the sample gets liquefied. At each test, the ratio of this value on the Liquid limit of the tested specimen is determined in order to be used in the development of the new approach (Table 1).

\section{Cyclic Triaxial Shear Test Results CTT}

The Cyclic Triaxial Tests (CTT) results allows to differentiate between a liquefiable and a non-liquefiable material when reaching one of the two following conditions; either the excess pore water pressure reaches the value of the consolidation stress $\Delta \mathrm{u}=\sigma^{\prime} \mathrm{c}$ or the peak-to-peak axial strain within a cycle is equal to $5 \%$. In this paragraph, the results of the saturation degree variation as well a comparison of the three samples responses to cyclic shearing are discussed in order to evaluate the NCNo susceptibility to liquefaction.

Figure 3 illustrates the effect of the degree of saturation $\left(S_{R}\right)$ variation on the liquefaction properties in the case of laterites samples. The obtained shapes of the curves are in accordance with those found by Pecker (1984) when analyzing the effect of the 
Table 1. CTT results on NCNo samples

\begin{tabular}{|c|c|c|c|c|}
\hline Samples & $<80 \mu \mathrm{m}(\%)$ & $>2 \mathrm{~mm}(\%)$ & IP (\%) & $\mathrm{W}_{\mathrm{c}} / \mathrm{LL}$ \\
\hline \multicolumn{5}{|l|}{ Laterites } \\
\hline L1 & 100 & - & 15 & 0.86 \\
\hline $\mathrm{L} 2$ & 92 & - & 16 & 0.7 \\
\hline L6 & 87.5 & - & 6 & 0.63 \\
\hline L7 & 86.6 & - & 15 & 0.65 \\
\hline Mean value & 88.47 & - & 12.56 & 0.72 \\
\hline \multicolumn{5}{|c|}{ Earthy saprolites } \\
\hline ES1 & 78 & - & 43 & 0.71 \\
\hline ES2 & 55.6 & - & 48 & 0.56 \\
\hline ES4 & 93.8 & - & 51 & 0.57 \\
\hline ES5 & 33.8 & - & 61 & 0.58 \\
\hline Mean value & 66.85 & - & 45 & 0.67 \\
\hline \multicolumn{5}{|c|}{ Grainy saprolites } \\
\hline GS1 & 40 & 40 & 9 & 0.7 \\
\hline GS2 & 37 & 48 & 11 & 0.67 \\
\hline GS3 & 47 & 34 & 19 & 0.55 \\
\hline GS4 & 36 & 42 & 24 & 0.46 \\
\hline GS9 & 42 & 33 & 16 & 0.64 \\
\hline Mean value & 39 & 40.62 & 17.7 & 0.64 \\
\hline
\end{tabular}

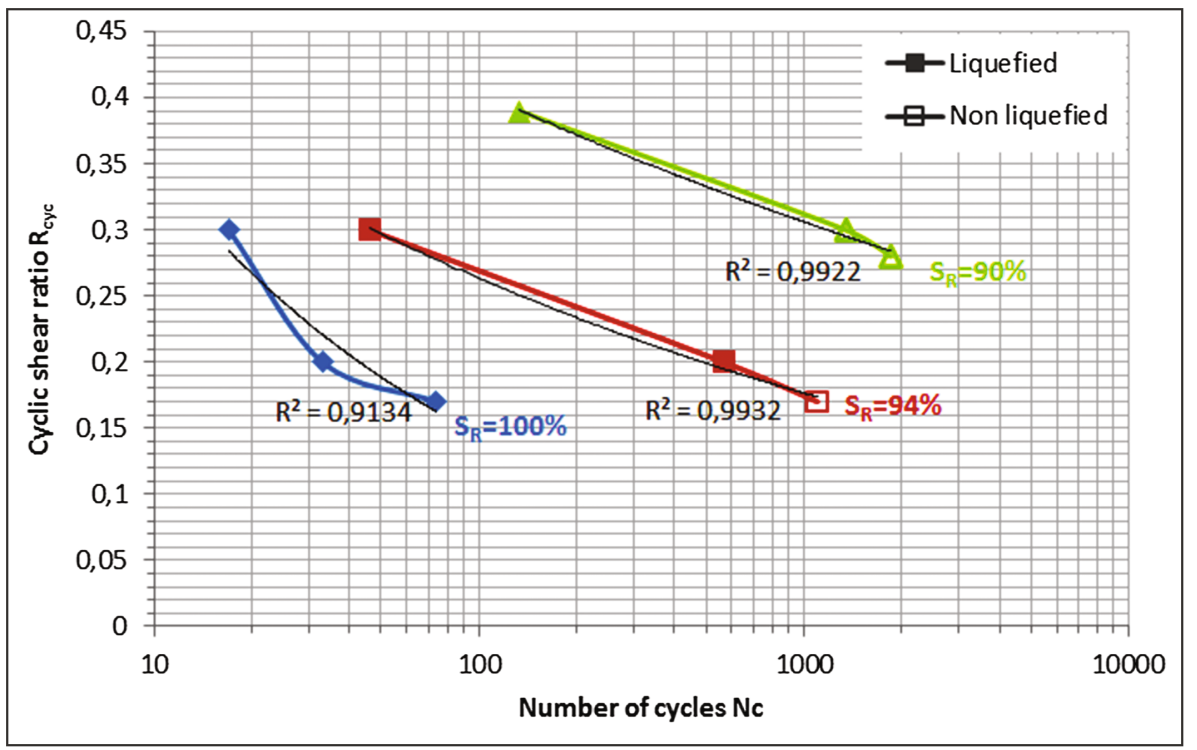

Fig. 3. Impact of the degree of saturation variation on the liquefaction properties in the case of Laterite samples 
degree of saturation on the cyclic shear resistance CSR of a soil. It is mentioned that the required number of cycles to trigger liquefaction when the sample is partially saturated is higher than that when the sample is fully saturated. Therefore, the decrease of the degree of saturation improves the cyclic shear resistance of soils. This result is in accordance with the statement of Sherif et al. (1977) who proved that liquefaction resistance for soils increases with decreasing degree of saturation.

CTT were conducted on the three samples under the same $R_{\text {cyc }}=0.2$. It is noted that sample representing group 2 needs a higher number of cycles to liquefy in comparison with the two other groups. This difference may be attributed to the high plasticity of earthy saprolites $(\mathrm{PI}=43)$ which is the origin of the liquefaction delay. Actually, as reported by Alan F. Rauch, plastic fines usually create sufficient adhesion between the grains to limit the ability of larger particles to move into a denser arrangement and therefore to prevent liquefaction.

In contrast, sample from group 1 was the first to get liquefied compared to the two other groups. Hence, laterites are assumed to be less resistant to liquefaction than earthy and grained saprolites. This difference could be explained by the high percentage of fines in this sample (fraction $<80 \mu \mathrm{m}=100 \%$ ). In fact, Finn et al. (1988), Lade and Yamamuro (1997), Zlatovic and Ishihara (1995) reported that liquefaction resistance decrease as the fine content increase. Moreover, according to Liang et al. (2000), it is proven that the coarse particles take an important part in soil to resist liquefaction and this is the case of grainy saprolites. Indeed, soils with a higher percentage of gravels tend to mobilize higher strength during shearing, and dissipate excess pore pressures more rapidly than sands.

\section{Methods to Evaluate the Liquefaction Potential}

In this section, the widely used empirical approaches to assess the liquefaction susceptibility of soils are presented. Afterwards, an attempt to develop a new empirical method adapted to NCNo is introduced.

\subsection{Existing Empirical Approaches}

Many empirical methods have been developed in order to predict the liquefaction susceptibility of soils. These approaches have been developed to assess the soil potential liquefaction using different combinations of soil characteristics.

To begin with, Tsuchida (1970) proposed particle size distribution boundary curves, using the results of sieve analyses on soils that did or did not liquefy during past earthquakes. Thus, representing the grain size curve of any soil on this graph, allows deducing its liquefaction potential.

Besides, Seed and Idriss (1982) stated that cohesive soils which are susceptible to liquefaction must fulfill the following criteria (combined):

- Percent finer than $0.005 \mathrm{~mm}<15 \%$

- Liquid Limit (LL) $<35 \%$

- Water Content $>0.9 \times$ Liquid Limit 
If soils with these characteristics, plot below the A-line on the Plasticity chart, the best means of determining their cyclic loading characteristics is by additional test. Otherwise, clayey soils may be considered non-vulnerable to liquefaction.

In addition, the widely used Chinese criteria as presented by Koester (1992) on Fig. 4 showed that based on the soil representation on the Casagrande graph potentially liquefiable and non-liquefiable soils can be distinguished.

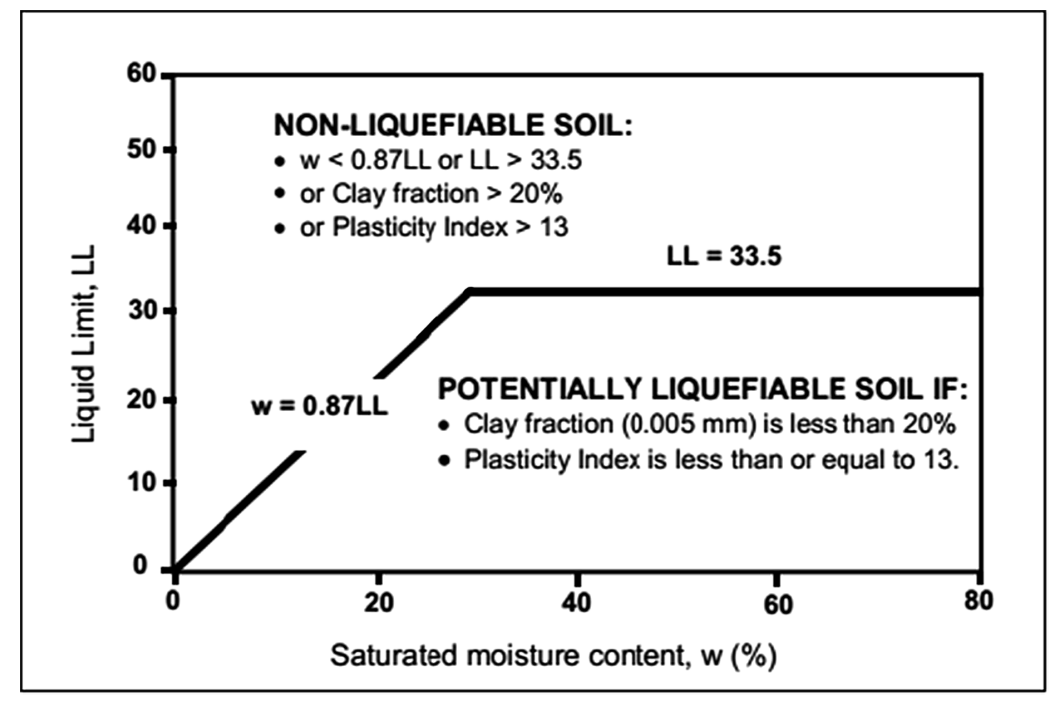

Fig. 4. Chinese Criteria Adapted to ASTM Definitions of Soil Properties (Perlea et al. 1999)

Furthermore, Andrews and Martin (2000) developed an empirical approach based on LL and percentage of fraction passing $2 \mu \mathrm{m}$ presented in the following table.

Last but not least, Seed et al. (2003) recommended an assessment chart shown in Fig. 8 which is divided into three zones; Zone A where soils are considered potentially susceptible to liquefaction if $\mathrm{Wc}>80 \% \mathrm{LL}$; Zone B where soils are considered potentially liquefiable with detailed laboratory testing recommended if $\mathrm{Wc}>85 \% \mathrm{LL}$ and Zone $\mathrm{C}$ where soils are considered generally not susceptible to classic cyclic liquefaction, although they should be checked for potential sensitivity.

\subsection{Development of a New Empirical Approach for NCNo Case}

Based on the existing widely used empirical approaches to evaluate the liquefaction potential of soils, a new method is proposed in this research which is more adapted to the case of NCNo. Most of the existing criteria are based on field observations where some soils got liquefied and some not under certain earthquakes. In this study, since it is not the case of a seismic solicitation, the results of CTT reproducing the transport conditions, are exploited to distinguish liquefiable soils from non-liquefiable ones and 
therefore a criterion for liquefaction is deduced based on the soil's physical and mechanical characterization.

\section{Results}

\subsection{Evaluation of NCNo Liquefaction Potential Based on Existing Empirical Methods}

The liquefaction susceptibility of NCNo samples was evaluated by means of the existing empirical approaches widely used in para-seismic analysis.

First, the grading ranges of each NCNo type was added to Tsuchida (1970) chart. It is seen from Figs. 5, 6 and 7 that all NCNo samples curves pass through both the 'Potentially Liquefiable' and 'Most Liquefiable Soil' boundaries. Therefore, according to this criterion and based on the representative grading ranges of each NCNo type, it can be concluded that the NCNo are susceptible to liquefaction under certain circumstances. Further, it should be mentioned when comparing the three obtained graphs that the most liquefiable type of NCNo is the Group 1 since its grading ranges falls exactly between the boundaries of potentially liquefiable soils. However, for Group 2 and 3 of NCNo only a part of their grain size distribution curves are plotted inside the boundaries defined by Tsuchida (1970).

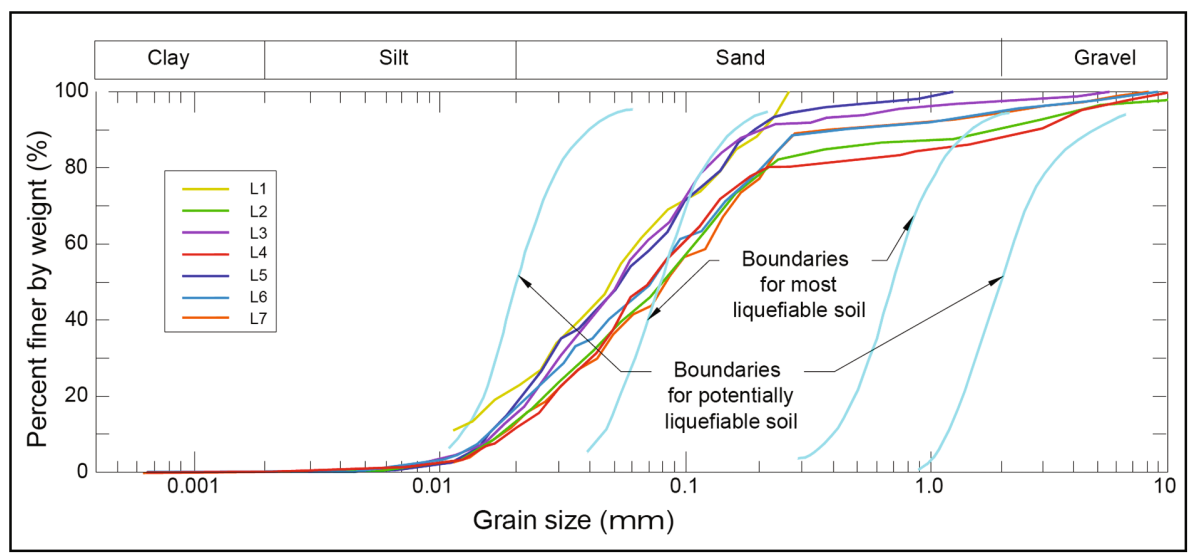

Fig. 5. Representation of the grain size distributions of Laterites NCNo on the Tsuchida graph

However, conforming to Seed and Idriss (1982) approach, NCNo are not prone to liquefaction since all their Liquid limits are above $35 \%$ and for all tested samples the water content does not exceed $0.9 \times$ Liquid Limit (Cf. Table 1).

Moreover, according to the widely used Chinese criteria as presented by Koester (1992) NCNo are classified as non-liquefiable soils since all Liquid limits are above $33.5 \%$ and all the water content does not exceed $0.87 \times$ Liquid Limit $(\mathrm{Cf}$. Table 1). 


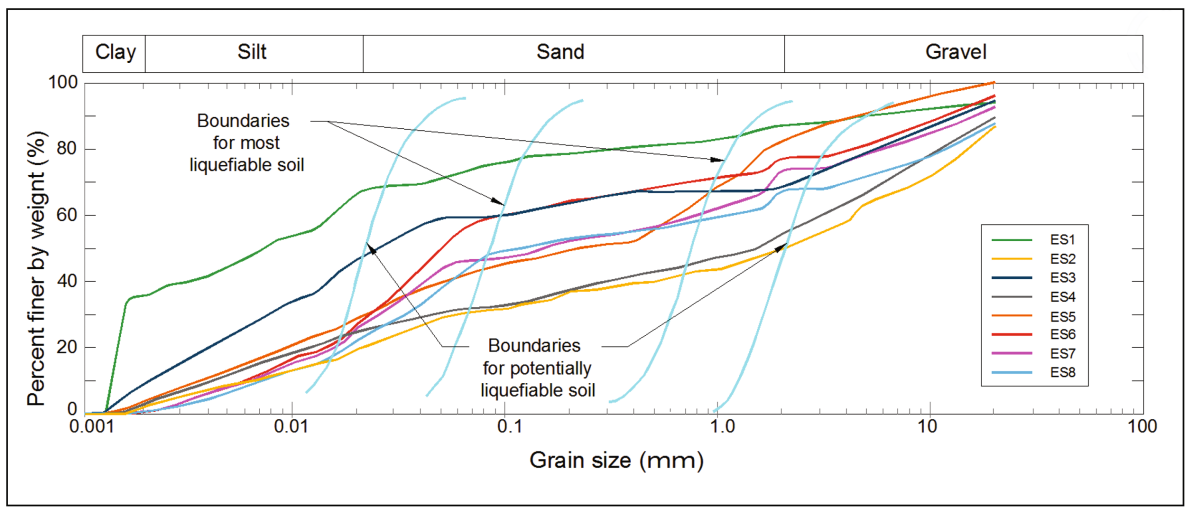

Fig. 6. Representation of the grain size distributions of Earthy Saprolites NCNo on the Tsuchida graph

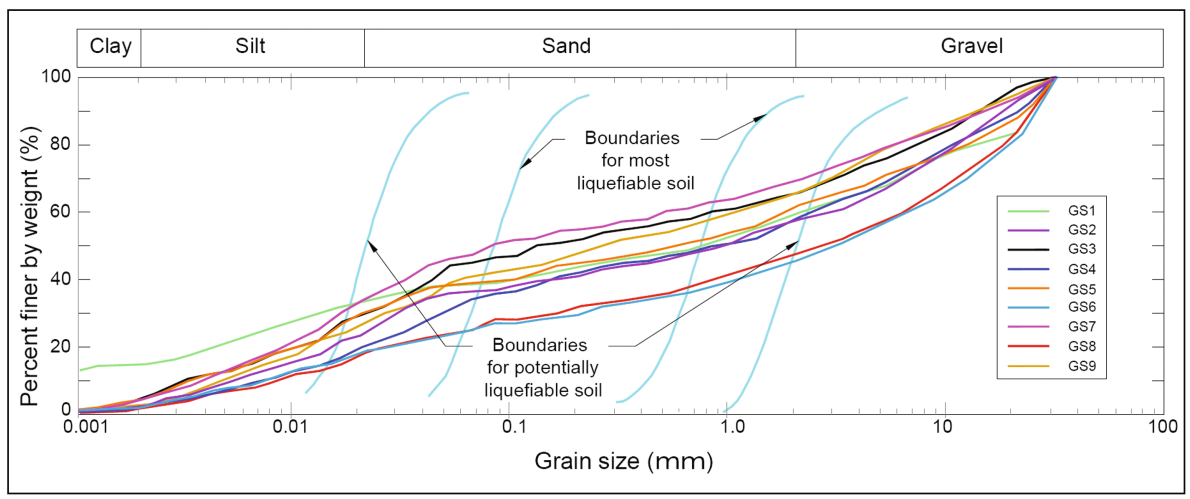

Fig. 7. Representation of the grain size distributions of Grainy Saprolites NCNo on the Tsuchida graph

In addition, following Andrews and Martin (2000) method, the three types of lateritic soils require further studies since their LL values are higher than $32 \%$ and their Minus $2 \mu \mathrm{m}$ fraction is generally less than $10 \%$ (Cf. Table 2).

Table 2. Liquefaction susceptibility criteria by Andrews and Martin (2000)

\begin{tabular}{l|l|l}
\hline & LL $<32$ & LL $\geq 32$ \\
\hline $\begin{array}{l}\text { Minus } 2 \mu \mathrm{m} \\
\text { fraction }<10 \%\end{array}$ & Susceptible to liquefaction & $\begin{array}{l}\text { Further studies required [Consider } \\
\text { plastic non-clay sized grains] }\end{array}$ \\
\hline $\begin{array}{l}\text { Minus } 2 \mu \mathrm{m} \\
\text { fraction } \geq 10 \%\end{array}$ & $\begin{array}{l}\text { Further studies required [Consider } \\
\text { plastic non-clay sized grains] }\end{array}$ & Not susceptible to liquefaction \\
\hline
\end{tabular}


Besides, the representation of NCNo on the graph recommended by Seed et al. (2003) showed that all the tested samples are plotted in zone $\mathrm{C}$ and thus are considered non susceptible to classic cyclic liquefaction, although they should be checked for potential sensitivity (Fig. 8).

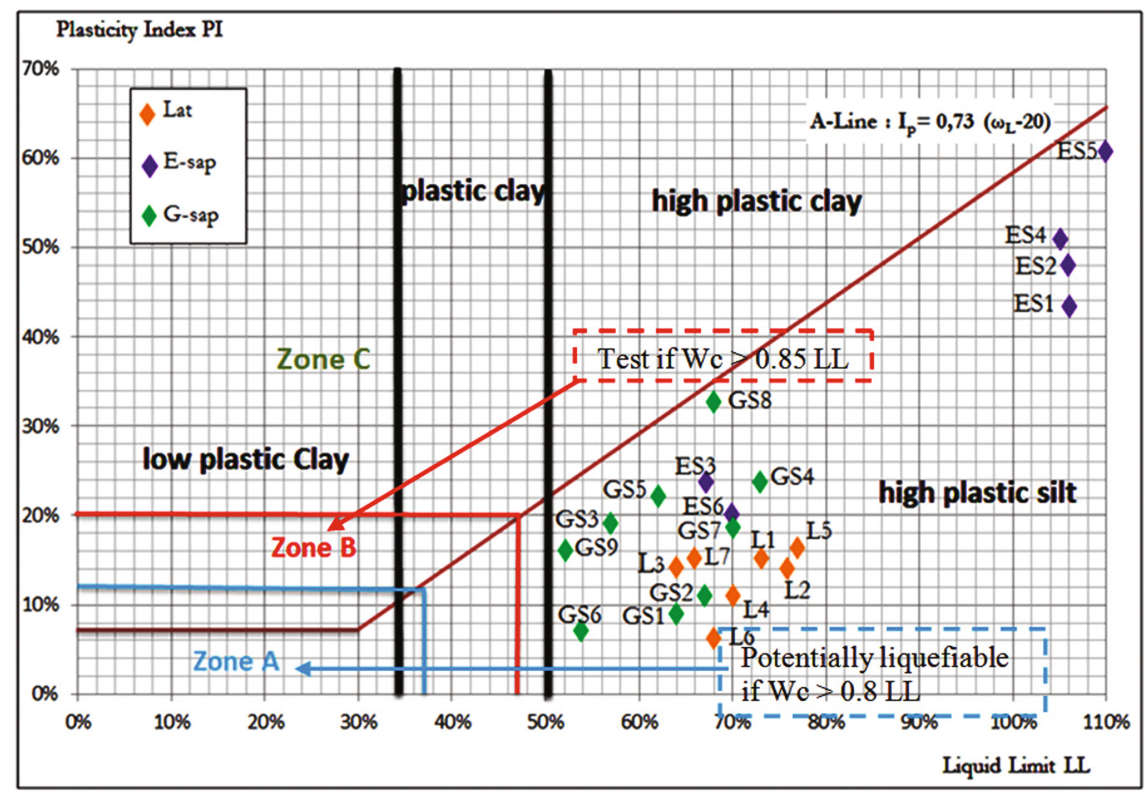

Fig. 8. Representation of the tested lateritic soils on Seed et al. (2003) recommended chart

Although these methods are well known and widely used, their usability is in doubt since they do not allow asserting on the liquefaction potential of NCNo. In fact while some of these methods consider that the tested Nickel ore samples are non-liquefiable, others claim they are rather susceptible to liquefaction or even liquefiable soils. This disagreement may be due to first, the fact that most of these empirical approaches were developed primarily for sands and not particularly for this type of soils (highly plastic silts). Second, these methods are based on observations of soil behavior under seismic loading which is doubtless a different solicitation comparing to the one due to swell effect.

For these reasons, in the following paragraph an adapted method to NCNo based on their physical and mechanical characterization is proposed in order to assess their liquefaction potential during maritime transport. 


\subsection{New Proposed Method for Evaluating the Liquefaction Potential of NCNo}

As mentioned before, the existing empirical approaches used in para-seismic analysis are not adopted to the New Caledonian Nickel ores. Therefore a new method to evaluate the liquefaction potential of this type of soil when exposed to the swell solicitations is developed. This approach is mainly based on the Seed and Idriss (1982) method and Seed et al. (2003) criteria adding appropriate modifications to fit with the tested samples according to Cyclic Triaxial Test (CTT) results (Cf. Table 1). Moreover, taking into account the heterogeneity of $\mathrm{NCNo}$, a criterion for each ore type is elaborated considering its specificity compared to the others (Cf. Table 3). These approaches are applicable for fully saturated samples.

Table 3. New approach for liquefaction assessment of New Caledonian Nickel ore under the swell effect

\begin{tabular}{|c|c|c|}
\hline \multicolumn{3}{|c|}{$\begin{array}{l}\text { New approach for liquefaction assessment of New Caledonian Nickel } \\
\text { ore under the swell effect }\end{array}$} \\
\hline Laterites & Earthy saprolites & Grainy saprolites \\
\hline $\begin{array}{l}\text { - Infra } 80 \mu \mathrm{m}>80 \% \\
\text { - IP } \geq 10 \% \\
\text { - Wc }>0,6 \mathrm{LL}\end{array}$ & $\begin{array}{l}\text { - } \text { Infra } 80 \mu \mathrm{m} \geq 50 \% \\
\text { - } \mathrm{MBV} \geq 5 \\
\text { - } \mathrm{IP} \geq 30 \% \\
\text { - } \mathrm{Wc}>0,55 \mathrm{LL}\end{array}$ & $\begin{array}{l}\text { - Supra } 2 \mathrm{~mm}>30 \% \\
\cdot \mathrm{IP} \geq 12 \% \\
\cdot \mathrm{Wc}>0,5 \mathrm{LL}\end{array}$ \\
\hline
\end{tabular}

\section{Conclusions}

First, the interpretation of physical characterization tests carried on NCNo allowed identifying three major types of this material:

- Group 1: Laterites which are very fine soils having most particles smaller than $80 \mu \mathrm{m}$. Based on their characterization tests, they are classified as highly plastic silty sands.

- Group 2: Earthy saprolites which are sandy silts containning a small fraction of coarse particles (>2 mm) not exceeding 30\%. According to the United Soil Classification System (LCPC-USCS), this soil is a high plastic silt having a high clay content $(\mathrm{MBV}>5)$.

- Group 3: Grainy saprolites are grainy sands having a high fraction of coarse particles $(>30 \%)$.

Second, the discussion of CTT results conducted on the three types of NCNo proved that these latters behave differently under the same solicitations. In fact, it is mentioned that earthy saprolites may be the less liquefiable type of NCNo. This high resistance to cyclic shearing may be attributed to the high plasticity of this ore (PI = 43) which is believed to contribute to the liquefaction delay. On the other hand, laterites appears to be the most susceptible type of NCNo to liquefaction since they acquires the less number of cycles to reach the criteria. This difference was explained 
by the high percentage of fines in this sample (fraction $<80 \mu \mathrm{m}=100 \%$ ). For the grainy saprolites, it is proven that the coarse particles take an important part in soil to resist liquefaction.

Afterwards, the evaluation of the liquefaction potential of NCNo by means of the existing methods hadn't provided reliable results to conclude. In fact, according to Tsuchida (1970) chart, all three types of NCNo appear to be susceptible to liquefaction. However, conforming to Seed and Idriss (1982) approach as well as the Chinese criteria as presented by Koester (1992), NCNo are not prone to liquefaction since they are characterized by high vales of Liquid limits and for all tested samples the water content does not exceed $0.87 \times$ Liquid Limit.

Finally, a new method adapted to NCNo was developed to assess the susceptibility of each type of ore to liquefaction. This approach has been inspired from the existing criteria and based on the physical and mechanical test results.

Acknowledgments. This research has been developed with the financial support of CNRT (Centre National de Recherche Technique "Nickel et son Environnement") and SEM (Syndicat des Producteurs-Exportateurs et Exportateurs de Minerai de Nickel de NC) in the scope of Rheolat I and II projects 2011-2016. We thank them both for providing insight and expertise that greatly assisted this research. We would also like to show our gratitude to the CERMES-Navier laboratories who has conducted the physical characterization and the Cyclic Triaxial tests.

\section{References}

Andrews, D.C.A., Martin, G.R.: Criteria for liquefaction of silty soils. In: Proceedings of 12th WCEE, Auckland, New Zealand (2000)

Finn, W.D.L.: Dynamic analysis in geotechnical engineering. In: Proceedings, Earthquake Engineering and Soil Dynamics II - Recent Advances in Ground Motion Evaluations. Geotechnical Special Publication, ASCE, vol. 20, pp. 523-591 (1988)

IMSBC: Adoption of The International Maritime Solid Bulk Cargoes Code (2008), Annex 3, Resolution MSC.268 (85) (2008)

Koester, J.P.: The influence of test procedure on correlation of Atterberg limits with liquefaction in fine-grained soils. Geotech. Test. J. 15(4), 352-360 (1992). ASTM

Koromila, I.A., et al.: Experimental investigation of cargo liquefaction and impact on the stability of a bulk - carrier. In: Proceedings of the 13th International Ship Stability Workshop, pp. 1-7 (2013)

Lade, P.V., Yamamuro, J.A.: Effects of non-plastic fines on static liquefaction of sands. Can. Geotech. J. 34(6), 918-928 (1997)

Liang, R.W., et al.: Effect of clay particle content on liquefaction of soil. In: 12th World Conference on Earthquake Engineering, Auckland, New Zealand (2000)

Pecker, A.: Dynamique des sols «Collection géotechnique», 259 p. Presses de l'École nationale des ponts et chaussées, Paris (1984)

Perlea, V.G., Koester, J.P., Prakash, S.: "How Liquefiable are Cohesive Soils?” In: Proceedings of the Second International Conference on Earthquake Geotechnical Engineering, Lisbon, Portugal, vol. 2, pp. 611-618 (1999)

Seed, H.B., Idriss, I.M.: Ground motions and soil liquefaction during earthquakes, p. 134. Earthquake Engineering Research Institute, Berkeley (1982) 
Seed, R.B., et al.: Recent advances in soil liquefaction engineering: a unified and consistent framework. EERC-2003-06. Earthquake Engineering Research Institute, Berkeley (2003)

Sherif, M.A., et al.: Saturation effect on initial soil liquefaction. J. Geotech. Eng. Div. 103, 914-917 (1977). American Society of Civil Engineers

Tsuchida, H.: Prediction and countermeasure against liquefaction in sand deposits. Abstract of the Seminar of the Port and Harbour Research Institute, Ministry of Transport, Yokosuka, Japan, pp. 3.1-3.33 (1970)

Zlatovic, S., Ishihara, K.: On the influence of non-plastic fines on residual strength. In: Proceedings of IS-Tokyo 1995, First International Conference on Earthquake Geotechnical Engineering, vol. 1, pp. 239-244 (1995) 